\title{
Desafios do egresso de enfermagem na inserção ao mercado de trabalho: uma revisão
}

\section{da literatura}

Challenges of nursing egress in the insert to the labor market: a literature review

\section{Desafíos de la salida de enfermería en el inserto al mercado laboral: revisión de la literatura}

Vinícius Santos Braz da Cunha

ORCID: https://orcid.org/0000-0001-9306-1782 Universidade Iguaçu, Brasil

E-mail: vinicios_vyny@hotmail.com

Greyce Kelly Souza Motta Alcoforado

ORCID: https://orcid.org/0000-0002-1237-6932 Universidade Iguaçu, Brasil

E-mail: motta.greyce@hotmail.com

Wanderson Alves Ribeiro

ORCID: https://orcid.org/0000-0001-8655-3789

Universidade Federal Fluminense, Brasil Universidade Iguaçu, Brasil

E-mail: nursing_war@hotmail.com

Marluce Conceição dos Santos Almeida

ORCID: https://orcid.org/0000-0003-0629-0646 Universidade Iguaçu, Brasil

E-mail: allmeid8@gmail.com

Joelma Zoroastro dos Santos Souza

ORCID: https://orcid.org/0000-0002-9554-2544 Universidade Iguaçu, Brasil

E-mail: barandof@gmail.com

Elisa Santana Daniel

ORCID: https://orcid.org/0000-0002-8895-7776 Universidade Iguaçu, Brasil

E-mail: elisasantanadaniel@gmail.com Érica Souza da Silva

ORCID: https://orcid.org/0000-0002-8667-2531 Universidade Iguaçu, Brasil

E-mail: ericassilva32@gmail.com

Renata Alves Fonseca

ORCID: https://orcid.org/0000-0002-5311-949X Universidade Iguaçu, Brasil

E-mail: renata.fonseca98@gmail.com

Amanda Gomes de Moura Duarte

ORCID: https://orcid.org/0000-0001-6482-7822 Universidade Iguaçu, Brasil

E-mail: amandinha13gmd@icloud.com

\section{Resumo}

O ensino superior em Enfermagem busca proporcionar aos futuros profissionais uma formação generalista, de maneira que possam exercer o pensamento crítico-reflexivo diante das diversas e desafiadoras situações do cotidiano em saúde, baseando sua conduta nos princípios éticos e bioéticos. Essas mudanças reafirmam a necessidade e o dever dessas instituições de formarem profissionais enfermeiros capacitados para atender às necessidades ampliadas de saúde da população com ênfase no Sistema Único de Saúde (SUS) e assegurar a integralidade da atenção e a qualidade e humanização do atendimento. Trata-se de uma revisão integrativa, com objetivo de descrever os desafios do egresso de enfermagem na inserção ao mercado de trabalho. Após a associação de todos os descritores foram selecionados 18 artigos. Posterior à leitura reflexiva emergiram três categorias: Principais inquietações do egresso de enfermagem na inserção ao mercado de trabalho; Contribuições do processo de formação da graduação em enfermagem na sua inserção ao mercado de trabalho; Formação na graduação em enfermagem e impacto na atuação profissional na perspectiva de egressos. Conclui-se que, a partir da construção de uma leitura reflexiva baseada nos artigos teóricos utilizados para construção deste ensaio, evidenciou em grandes partes dos estudos utilizados que as maiores porcentagens deles vislumbram, o comprometimento no processo de ensino-aprendizagem como grande ofensor e contribuir da insegurança deste enfermeiro recém-formado.

Palavras-chave: Mercado de trabalho; Enfermagem; Educação em enfermagem. 


\begin{abstract}
Higher education in Nursing seeks to provide future professionals with general training, so that they can exercise critical-reflective thinking in the face of diverse and challenging everyday health situations, basing their conduct on ethical and bioethical principles. These changes reaffirm the need and duty of these institutions to train professional nurses trained to meet the expanded health needs of the population with an emphasis on the Unified Health System (SUS) and to ensure comprehensive care and the quality and humanization of care. It is an integrative review, with the objective of describing the challenges of nursing graduates in entering the job market. After associating all descriptors, 18 articles were selected. After the reflective reading, three categories emerged: Main concerns of the nursing graduate when entering the job market; Contributions of the nursing graduation formation process in its insertion in the job market; Nursing undergraduate training and impact on professional performance from the perspective of graduates. It is concluded that, from the construction of a reflective reading based on the theoretical articles used for the construction of this essay, it was evident in large parts of the studies used that the largest percentage of them envision, the commitment in the teaching-learning process as a great offender and contribute of the insecurity of this newly graduated nurse.
\end{abstract}

Keywords: Job market; Nursing; Nursing educatio.

\begin{abstract}
Resumen
O ensino superior em Enfermagem busca proporcionar aos futuros profissionais uma formação generalista, de maneira que possam exercer o pensamento crítico-reflexivo diante das diversas e desafiadoras situações do cotidiano em saúde, baseando sua conduta nos princípios éticos e bioéticos. Essas mudanças reafirmam a necessidade e o dever dessas instituições de formarem profissionais enfermeiros capacitados para atender às necessidades ampliadas de saúde da população com ênfase no Sistema Único de Saúde (SUS) e assegurar a integralidade da atenção e a qualidade e humanização do atendimento. Trata-se de uma revisão integrativa, com objetivo de descrever os desafios do egresso de enfermagem na inserção ao mercado de trabalho. Após a associação de todos os descritores foram selecionados 18 artigos. Posterior à leitura reflexiva emergiram três categorias: Principais inquietações do egresso de enfermagem na inserção ao mercado de trabalho; Contribuições do processo de formação da graduação em enfermagem na sua inserção ao mercado de trabalho; Formação na graduação em enfermagem e impacto na atuação profissional na perspectiva de egressos. Se concluye que, a partir de la construcción de una lectura reflexiva a partir de los artículos teóricos utilizados para la construcción de este ensayo, se evidenció en gran parte de los estudios utilizados que el mayor porcentaje de ellos vislumbra, el compromiso en la enseñanza-aprendizaje. proceso como un gran delincuente y contribuir a la inseguridad de esta enfermera recién egresada.
\end{abstract}

Palabras clave: Mercado de trabalho; Enfermagem; Educação em enfermagem.

\title{
1. Introdução
}

Ingressar no ensino superior no Brasil não tem sido um grande problema, todos os anos, há muitas ofertas de vagas para se fazer parte do meio acadêmico, e assim, milhares de pessoas cruzam as portas das Universidades (Brasil, 2015).

Neto et al., (2007) corrobora que a educação superior vem sendo desafiada a romper paradigmas que a colocam na direção de uma formação com pertinência social e coerência com as Diretrizes Curriculares Nacionais (DCN), ou seja, com as necessidades de transformação do processo de formação profissional.

As universidades de enfermagem têm sofrido modificações no que se refere a sua relação com as condições econômicas, políticas e ideológicas de cada período. No país, a partir das primeiras décadas do século XX, o campo de enfermagem vem ocupando lugar de destaque no setor saúde, constituindo a maior força de trabalho nessa área. Data também desse momento, o processo de laicização da profissão de enfermeira e a preocupação estatal em legislar sobre a sua formação e exercício profissional (Duarte et al., 2016).

No que se refere ao curso de graduação em enfermagem, vale informar que as Diretrizes Curriculares definem ainda, que a formação do enfermeiro tem por objetivo dotar o profissional dos conhecimentos requeridos para o exercício das seguintes competências e habilidades gerais: atenção à saúde, tomada de decisões, comunicação, liderança, administração e gerenciamento e educação permanente (Brasil, 2001).

O ensino superior em Enfermagem busca proporcionar aos futuros profissionais uma formação generalista, de maneira que possam exercer o pensamento crítico-reflexivo diante das diversas e desafiadoras situações do cotidiano em saúde, baseando sua conduta nos princípios éticos e bioéticos (Silva et al., 2019). 
Vale mencionar que, essa expectativa aponta para a transformação do perfil dos futuros enfermeiros, por meio da adoção de estratégias dirigidas ao campo de desenvolvimento dos profissionais, construídas com base nos princípios e diretrizes do sistema público de saúde, além de fundamentadas no conceito ampliado de saúde; na utilização de metodologias ativas de ensino-aprendizagem, que considerem o trabalho em saúde como eixo estruturante das atividades; no trabalho multiprofissional e transdisciplinar; na integração entre o ensino e os serviços de saúde; e no aperfeiçoamento da atenção integral à saúde da população (Neto et al., 2007).

Essas mudanças reafirmam a necessidade e o dever dessas instituições de formarem profissionais enfermeiros capacitados para atender às necessidades ampliadas de saúde da população com ênfase no Sistema Único de Saúde (SUS) e assegurar a integralidade da atenção e a qualidade e humanização do atendimento (Brasil, 2001).

De acordo com Oliveira (2017) o mercado de trabalho para enfermeiros iniciantes pode apresentar-se repleto de estresse e incertezas, ao mesmo tempo em que existe uma ansiedade por parte dos egressos em enfermagem em dar início às atividades profissionais, obrigando-o a superar o seu medo do desconhecido.

A primeira observação importante refere-se à representatividade da Enfermagem em relação ao total de ocupados da saúde, que engloba 3,5 milhões de pessoas, representando mais da metade de todos os trabalhadores. No entanto, esse contingente dá sinais de problemas de empregabilidade plena quando se aponta quase $5 \%$ de desemprego aberto e $4,5 \%$ de afastamento temporário da atividade profissional. Mostra ainda que $10 \%$ do contingente experimentaram desemprego aberto nos últimos 12 meses, sendo que, em alguns estados estes índices são muito mais graves denunciando o grave problema de desequilíbrio entre oferta e demanda desta orça de Trabalho (Machado et al., 2016).

Alguns dos elementos atuam como facilitadores na transição da vida acadêmica para a profissional, tal como a formação acadêmica calcada em bons embasamentos teóricos, a vivência de estágios extracurriculares, posicionamento institucional de motivação ao desenvolvimento educacional dos discentes e apoio por parte dos demais membros mais experientes da equipe de trabalho (Oliveira, 2017).

Certamente, é preciso pensar em uma formação profissional com orientação para o trabalho, capaz de integrar habilidades teóricas e também práticas, bem como atitudes, valores éticos e conhecimentos tanto gerais quanto específicos. Isso porque a rotina do enfermeiro envolve situações adversas, momentos em que é preciso que o profissional se posicione e tome decisões que podem ser importantes na vida de diversas pessoas. Portanto, a graduação é o passo inicial, e que não deve ser finalizado na formatura, já que a educação continuada em saúde configura uma alternativa eficaz para a melhoria da atuação e a redução de dificuldades do enfermeiro no mercado de trabalho, promovendo a constante atualização dos conhecimentos e atuação profissional (Oliveira, 2017).

Os cursos da área de saúde, geralmente, possuem no currículo atividades práticas, diante das quais os estudantes geralmente percebem suas limitações quanto ao conhecimento. Por conseguinte, os estudantes do curso de graduação enfermagem experimentam elevados níveis de estresse, sobretudo aqueles que cursam a graduação em Enfermagem, pela maior proximidade e permanência junto a pacientes e problemas de saúde destes (Oliveira, 2017).

Pesquisas referentes a esta temática, envolvendo estudantes universitários vêm sendo realizadas desde a década de 1980, entretanto para os graduandos de Enfermagem percebe-se que não há ênfase no seu estudo. Considerando que a população de estudantes universitários tem crescido ao longo dos últimos anos, o monitoramento preciso de informações demográficas, comportamentais e socioambientais que possam estar relacionadas com a saúde e com o desempenho acadêmico é fundamental para a formulação de políticas governamentais e programas de intervenção para esse grupo populacional (Souza et al., 2013). 
Devido à complexidade do curso de graduação e o lidar com os limites humanos, os estudantes de Enfermagem podem desenvolver sentimentos de incapacidade frente às atividades exigidas durante a formação e ainda, sentem-se inquietos e preocupados com as próximas etapas, posterior a fim da graduação (Hirsch et al., 2015).

Diante disso, ressalta-se que as pressões biopsicossociais são responsáveis por desequilíbrios na homeostase do indivíduo, prejudicando o desempenho nas mais variadas circunstâncias. Essas pressões geradoras de estresse são vivenciadas em diversas oportunidades na vida pessoal, social, profissional e durante a trajetória acadêmica (Silva \& Goulart, 2014). Além de todas as características supracitadas, ressalta-se a grande inquietação com o primeiro emprego que, de acordo estudo realizado pelo Conselho Federal de Enfermagem (COFEN), 65,9\% dos profissionais de enfermagem referem dificuldades para primeira oportunidade laborativa. A área já apresenta situação de desemprego aberto, com 10,1\% dos profissionais entrevistados relatando situações de desemprego nos últimos 12 meses (Cofen, 2015).

Quando se trata do egresso em enfermagem, a insegurança e o medo peranteas dificuldades tornam-se desafios iniciados no processo de admissão ao primeiro emprego, continuando com seu processo de adaptação ao serviço. Assim, o desafio pode ser entendido como um estímulo para a superação de uma situação adversa. Envolve ainda a possibilidade de transformação de tal situação, em subsídio para o próprio crescimento, desenvolvimento ou conquista. Isso porque, ao adentrar ao universo de trabalho, o egresso em enfermagem encontra-se perante situações adversas que decorrem da falta de integração entre o que é ensinado no curso de graduação e a realidade no atendimento de saúde (Oliveira, 2017).

Complementa-se que as principais dificuldades enfrentadas pelos enfermeiros em início de carreira, abordando que dentro de sua amostra de pesquisa empírica, os profissionais recém-graduados, quando inseridos no mundo do trabalho, enfrentam situações de extremo estresse decorrentes de uma ausência de concordância entre a aprendizagem na vida acadêmica e a prática profissional (Silva et al., 2010).

O estudo justifica-se, pois, promover o aprimoramento da qualidade do ensino de graduação nos cursos da saúde importa tornar claro aos diferentes atores interessados na mudança, os novos referenciais que devem ser captados pelos processos de avaliação, a fim de subsidiar não apenas a formulação de políticas públicas, mas para sustentar as decisões que orientam o trabalho pedagógico, que se faz necessário para dar conta das rupturas necessárias ao novo paradigma da formação em saúde (Neto et al., 2007).

Quanto à formação da Enfermagem, detentora do maior contingente de trabalhadores do setor saúde, tem-se vivenciado significativas transformações, de modo a acompanhar o contexto histórico, político, econômico e social que repercute na produção sanitária e, consequentemente, na qualidade de vida da população brasileira. Para que isso ocorra e o processo de trabalho em Enfermagem seja coerente com as demandas sociais, a formação de Enfermeiros com qualidade é condição sine qua non para a aquisição de conhecimentos científicos, habilidades técnicas, raciocínio crítico-reflexivo e atitudes, imprescindíveis para o desenvolvimento do cuidado holístico e humanizado voltado para as demandas de saúde individual e coletiva (Mattia et al., 2018).

O presente estudo pode ser facilitador no processo de identificação sobre as possíveis inquietações vivenciadas pelo acadêmico de enfermagem. Com este auxílio o acadêmico obterá informação dos fatores que aumentam o nível de estresse ainda no fim do processo de ensino-aprendizagem, sendo sua realização pragmática para efetuar as estratégias propostas, o que desencadeará resultados eficazes no processo de aprendizagem e na visão holística deste futuro profissional.

Por sua vez, a pesquisa poderá contribuir também para a sociedade com a diminuição das reações adversas que podem ser provocadas por egresso de enfermagem que são acometidos pelos fatores estressores, o que resultará no aumento do desempenho profissional e na realização de maior qualidade na assistência prestada aos clientes, com o objetivo de diminuir o tempo de internação e possibilitar uma recuperação mais eficaz, mesmo quando estes pacientes necessitam de tratamento intensivo, o que irá proporcionar menos gastos as instituições hospitalares. 
Frente a isso emergiu as seguintes questões norteadoras: Quais são as principais inquietações do egresso em enfermagem na inserção ao mercado de trabalho e quais as contribuições do processo de formação da graduação em enfermagem na sua inserção no mercado de trabalho?

Com base nisso, os objetivos desse estudo são compreender as inquietações do egresso de enfermagem na inserção ao mercado de trabalho, descrever as principais inquietações do egresso de enfermagem na inserção ao mercado de trabalho e identificar contribuições do processo de formação da graduação em enfermagem na sua inserção no mercado de trabalho.

\section{Metodologia}

Trata-se de uma pesquisa de revisão integrativa, inclui as concepções teóricas de abordagem, o conjunto de técnicas que possibilitam a construção da realidade e o sopro divino do potencial criativo do investigador (Minayo, 2002).

Para o profissional de enfermagem a análise de pesquisa trará apoio para realizar devidas decisões e progresso na prática clínica, tornando os resultados de pesquisas mais acessíveis, pois o profissional tem acesso a diversas pesquisas realizadas em um único estudo (Mendes et al., 2008).

Na primeira etapa ocorre a elaboração da questão norteadora que é: Quais são as principais inquietações do egresso de enfermagem na inserção ao mercado de trabalho? Na segunda etapa definiram-se os critérios de inclusão para seleção, que foram: artigos disponíveis em português, no período de 2015 a 2019, com os descritores: Mercado de Trabalho; Enfermagem; Educação em Enfermagem. Assim a revisão foi realizada através da Biblioteca Virtual de Saúde (BVS), nas seguintes bases de dados: LILACS, BDENF e Google Acadêmico, no período de abril e maio de 2020.

Ressalto que os critérios de exclusão estabelecidos foram: indisponibilidade de acesso, publicações em mais de uma base de dados, resumo, textos na forma de projetos, em outros idiomas, fora do recorte temporal definido nos critérios de inclusão e todos os artigos que não são articulados a temática.

Quadro 1: Descritores Isolados.

\begin{tabular}{|c|c|c|c|c|c|c|c|c|}
\hline Descritores & Total & 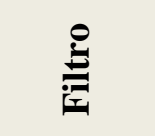 & 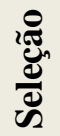 & $\stackrel{\sim}{8}$ & 율 & 홍 & $\stackrel{\infty}{\stackrel{\sim}{\sim}}$ & 호 \\
\hline $\begin{array}{l}\text { Mercado de } \\
\text { trabalho }\end{array}$ & 14.631 & 548 & 05 & 528 & 446 & 450 & 438 & 295 \\
\hline Enfermagem & 600.226 & 143.053 & 04 & 13.915 & .12 .406 & 13.298 & 13.652 & 8.502 \\
\hline $\begin{array}{l}\text { Educação em } \\
\text { enfermagem }\end{array}$ & 138.284 & 2.928 & 07 & 4.055 & 3.880 & 3.348 & 3.400 & 2.032 \\
\hline TOTAL & 753.141 & 146.529 & 16 & 18.498 & 16.732 & 17.096 & 17.490 & 10.829 \\
\hline
\end{tabular}

Fonte: Autores.

Ao utilizar os descritores Mercado de trabalho, obtivemos o total de 14.631, com o critério de inclusão limite Enfermagem e assunto principal Educação em enfermagem. Já com o descritor Enfermagem, evidenciamos 600.226, ao filtrar obtivemos 143.053, onde foram escolhidos 04 artigos. Com descritor Educação em enfermagem selecionamos 07 produções.

Dessa forma, o estudo evidenciou 753.141 produções, dos quais obtivemos resultados, onde foram encontrados 18 artigos. 
Quadro 2: Cruzamento dos descritores.

\begin{tabular}{|c|c|c|c|c|c|c|c|c|}
\hline Descritores & Total & $\stackrel{巳}{\stackrel{E}{E}}$ & ॠ్ & $\frac{n}{\bar{d}}$ & $\frac{b}{\bar{d}}$ & 공 & $\stackrel{\infty}{\bar{\sim}}$ & 를 \\
\hline $\begin{array}{c}\text { Mercado de } \\
\text { trabalho and } \\
\text { nfermagem and } \\
\text { Educação em } \\
\text { Enfermagem }\end{array}$ & 499 & 39 & 00 & 10 & 11 & 08 & 10 & 11 \\
\hline $\begin{array}{l}\text { Mercado de } \\
\text { trabalho and } \\
\text { Enfermagem }\end{array}$ & 1.640 & 83 & 00 & 14 & 22 & 16 & 17 & 14 \\
\hline $\begin{array}{l}\text { Mercado de } \\
\text { Trabalho and } \\
\text { Educação em } \\
\text { enfermagem }\end{array}$ & 499 & 39 & 00 & 06 & 09 & 06 & 10 & 08 \\
\hline $\begin{array}{c}\text { Enfermagem and } \\
\text { Educação em } \\
\text { Enfermagem }\end{array}$ & 138.284 & 2.928 & 04 & 543 & 623 & 677 & 636 & 449 \\
\hline TOTAL & 140.922 & 3.089 & 04 & 573 & 665 & 707 & 673 & 482 \\
\hline
\end{tabular}

Fonte: Autores.

Ao utilizar os descritores Mercado de trabalho and Enfermagem and Educação em Enfermagem, obtivemos o total de 499, ao filtrar obtivemos 39, no qual não selecionamos estudos pois não atenderam as nossas necessidades. Já com o cruzamento Mercado de trabalho and Enfermagem, evidenciamos 1.640, ao filtrar obtivemos 83 resultados, onde nenhum foi selecionado pois não atenderam as nossas necessidades.

Os descritores Enfermagem and Educação em Enfermagem captamos 138.284, ao filtrar obtivemos 2.928, onde selecionamos 04 artigos. Dessa forma, o estudo evidenciou 140.922 produções, sendo que somente 04 atendeu aos critérios de inclusão.

Quadro 3: Cruzamento dos descritores Google Acadêmico. 


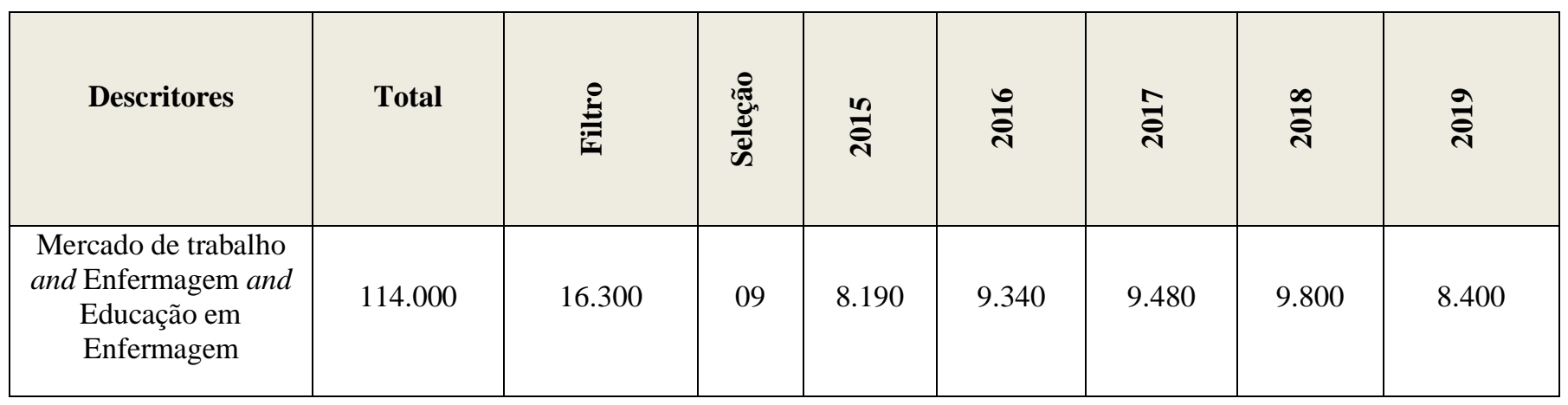

Fonte: Autores.

Após a busca na BVS, realizou-se a busca no Google Acadêmico, em que utilizamos como critério produções como manuais programas e artigos disponíveis em português, classificados por maior relevância nos primeiros 200 estudos evidenciados, como os descritores: Mercado de trabalho and Enfermagem and Educação em Enfermagem.

Na terceira etapa utilizamos um instrumento de coleta de dados, que tem como objetivo extrair as informações chaves de cada artigo selecionado.

Quadro 4: Levantamento estrutural dos artigos selecionados nas bases de dados da temática.

\begin{tabular}{|c|c|c|c|c|c|}
\hline Título & Periódico & Base de Dados & Ano & Objetivo & Conclusão \\
\hline $\begin{array}{l}\text { Formação acadêmica do } \\
\text { profissional de enfermagem e sua } \\
\text { adequação as atividades de } \\
\text { trabalho }\end{array}$ & $\begin{array}{l}\text { Rev. } \\
\text { latinoam. } \\
\text { enferm }\end{array}$ & Google Scholar & 2015 & $\begin{array}{l}\text { Identificar a formação } \\
\text { dos profissionais de } \\
\text { enfermagem e sua } \\
\text { adequação ao trabalho } \\
\text { que realizam, assim } \\
\text { como, a demanda de } \\
\text { formação continuada. }\end{array}$ & $\begin{array}{l}\text { Os profissionais de } \\
\text { enfermagem } \\
\text { consideram necessário } \\
\text { adequar a formação } \\
\text { continuada à atividade } \\
\text { de trabalho e trajetória } \\
\text { profissional. }\end{array}$ \\
\hline $\begin{array}{l}\text { Avaliação em estágio curricular na } \\
\text { graduação em enfermagem } \\
\text { experiências e dificuldades } \\
\text { vivenciadas por docentes }\end{array}$ & $\begin{array}{l}\text { Rev. de } \\
\text { educação } \\
\text { educare }\end{array}$ & Google Scholar & 2015 & $\begin{array}{l}\text { O objeto investigado foi } \\
\text { o processo avaliativo em } \\
\text { estágio curricular de um } \\
\text { curso de enfermagem, } \\
\text { com objetivo de } \\
\text { identificar e descrever as } \\
\text { experiências e } \\
\text { dificuldades vivenciadas } \\
\text { pelos docentes. }\end{array}$ & $\begin{array}{l}\text { A realização desse } \\
\text { estudo sobre avaliação } \\
\text { revelou que o tema é } \\
\text { relevante no processo } \\
\text { de ensino e } \\
\text { aprendizagem em } \\
\text { estágio curricular no } \\
\text { curso de enfermagem. }\end{array}$ \\
\hline $\begin{array}{c}\text { Formação na graduação em } \\
\text { enfermagem e impacto na atuação } \\
\text { profissional na perspectiva de } \\
\text { egressos }\end{array}$ & $\begin{array}{l}\text { Interface } \\
\text { Educação }\end{array}$ & Google Scholar & 2015 & $\begin{array}{l}\text { Verificar em que medida } \\
\text { a formação acadêmica } \\
\text { recebida, em suas } \\
\text { diferentes áreas habilitou } \\
\text { para o desenvolvimento } \\
\text { da prática profissional }\end{array}$ & $\begin{array}{l}\text { Conclui-se que o curso } \\
\text { deve resgatar a } \\
\text { formação nas áreas } \\
\text { indicadas como } \\
\text { frágeis em sua relação } \\
\text { com a inserção } \\
\text { laboral; repensar a } \\
\text { relação teoria e } \\
\text { prática, os seus } \\
\text { métodos de ensino e } \\
\text { as estratégias de } \\
\text { avaliação. }\end{array}$ \\
\hline $\begin{array}{l}\text { Enfermeiro egressos do currículo: } \\
\text { integrado e atuação profissional }\end{array}$ & $\begin{array}{l}\text { Rev enferm } \\
\text { UFPE on } \\
\text { line }\end{array}$ & BDENF & 2017 & $\begin{array}{l}\text { Verificar a inserção no } \\
\text { mercado de trabalho e a } \\
\text { atuação profissional de } \\
\text { egressos do Currículo } \\
\text { Integrado do Curso de } \\
\text { Enfermagem da } \\
\text { Universidade Estadual de }\end{array}$ & $\begin{array}{l}\text { Para muitos deles, a } \\
\text { empregabilidade é } \\
\text { uma realidade } \\
\text { constatada e atribuída } \\
\text { à formação e ao } \\
\text { cenário profissional da } \\
\text { região.. }\end{array}$ \\
\hline
\end{tabular}




\begin{tabular}{|c|c|c|c|c|c|}
\hline & & & & Londrina. & \\
\hline $\begin{array}{l}\text { Inserção profissional e carreira de } \\
\text { formandos e egressos brasileiros: } \\
\text { revisão da literatura }\end{array}$ & $\begin{array}{l}\text { Rev. bras. } \\
\text { orientac }\end{array}$ & LILACS & 2017 & $\begin{array}{l}\text { Desenvolvimento } \\
\text { profissional, ensino } \\
\text { superior, mercado de } \\
\text { trabalho }\end{array}$ & $\begin{array}{c}\text { Esta revisão de } \\
\text { literatura se propôs a } \\
\text { analisar artigos } \\
\text { nacionais que } \\
\text { tratassem do momento } \\
\text { transitório abrangendo } \\
\text { o final da graduação } \\
\text { até os anos iniciais do } \\
\text { exercício profissional.. }\end{array}$ \\
\hline $\begin{array}{l}\text { Formação em enfermagem e } \\
\text { mundo do trabalho: percepções de } \\
\text { egressos de enfermagem }\end{array}$ & Aquichán & Google Scholar & 2017 & $\begin{array}{l}\text { Descrever e analisar a } \\
\text { percepção de egressos do } \\
\text { curso de graduação em } \\
\text { enfermagem sobre o } \\
\text { processo de formação e o } \\
\text { mundo do trabalho em } \\
\text { saúde e enfermagem. }\end{array}$ & $\begin{array}{c}\text { Os participantes } \\
\text { apresentam um ponto } \\
\text { de vista crítico e uma } \\
\text { visão macroestrutural } \\
\text { sobre o mundo do } \\
\text { trabalho } \\
\text { contemporâneo } \\
\text { aproximada da } \\
\text { discussão de } \\
\text { sociólogos e estudioso } \\
\text { do trabalho. }\end{array}$ \\
\hline $\begin{array}{c}\text { Formação de enfermeiros centrada } \\
\text { na prática profissional: percepção } \\
\text { de estudantes e professores }\end{array}$ & $\begin{array}{l}\text { Rev. Gaucha } \\
\text { Enferm }\end{array}$ & Google Scholar & 2017 & $\begin{array}{l}\text { Analisar a percepção de } \\
\text { estudantes e professores } \\
\text { sobre o processo de } \\
\text { inserção do estudante na } \\
\text { prática profissional de } \\
\text { enfermagem. }\end{array}$ & $\begin{array}{l}\text { O estudo demonstrou } \\
\text { a importância da } \\
\text { inserção dos } \\
\text { estudantes no contexto } \\
\text { hospitalar para o } \\
\text { desenvolvimento da } \\
\text { aprendizagem, } \\
\text { permitindo maior } \\
\text { aproximação com a } \\
\text { realidade da profissão. }\end{array}$ \\
\hline $\begin{array}{l}\text { Egressos de enfermagem } \\
\text { potencialidades no processo de } \\
\text { formação profissional para } \\
\text { inserção no mercado de trabalho }\end{array}$ & $\begin{array}{l}\text { Indagatio } \\
\text { Didactica }\end{array}$ & Google Scholar & 2017 & $\begin{array}{c}\text { Conhecer as } \\
\text { potencialidades no } \\
\text { processo de formação } \\
\text { profissional para inserção } \\
\text { no } \\
\text { mercado de trabalho na } \\
\text { óptica de egressos de um } \\
\text { Curso de Graduação em } \\
\text { Enfermagem de Itajubá, } \\
\text { Minas Gerais }\end{array}$ & $\begin{array}{c}\text { Evidencia-se } \\
\text { a necessidade da } \\
\text { manutenção e } \\
\text { fortalecimento das } \\
\text { potencialidades } \\
\text { desenvolvidas no } \\
\text { processo } \\
\text { de formação do } \\
\text { profissional } \\
\text { enfermeiro } \\
\end{array}$ \\
\hline $\begin{array}{c}\text { O enfermeiro no mercado de } \\
\text { trabalho inserção competências e } \\
\text { habilidades }\end{array}$ & $\begin{array}{c}\text { Rev Bras } \\
\text { Enferm }\end{array}$ & Google Scholar & 2017 & $\begin{array}{l}\text { Caracterizar enfermeiros } \\
\text { egressos da Escola de } \\
\text { Enfermagem da } \\
\text { Universidade de São } \\
\text { Paulo (EEUSP), período } \\
\text { de } 2006 \text { a 2012; verificar } \\
\text { a inserção, as facilidades } \\
\text { e dificuldades desses } \\
\text { egressos no mercado de } \\
\text { trabalho e apreender suas } \\
\text { habilidades e } \\
\text { competências no mundo } \\
\text { do trabalho. }\end{array}$ & $\begin{array}{c}\text { Os resultados } \\
\text { evidenciam que a } \\
\text { EEUSP vem } \\
\text { preparando } \\
\text { enfermeiros para atuar } \\
\text { no mundo do trabalho, } \\
\text { conforme preceitos } \\
\text { das Diretrizes } \\
\text { Curriculares Nacionais }\end{array}$ \\
\hline $\begin{array}{c}\text { Enfermagem desafios e } \\
\text { dificuldades do início da carreira }\end{array}$ & $\begin{array}{l}\text { Rev. Enferm } \\
\text { faciplac }\end{array}$ & Google Scholar & 2017 & $\begin{array}{l}\text { Debater de maneira } \\
\text { conceitual sobre os } \\
\text { desafios e dificuldades } \\
\text { enfrentados pelos } \\
\text { enfermeiros em início de } \\
\text { carreira, em relação ao } \\
\text { mercado de trabalho. }\end{array}$ & $\begin{array}{c}\text { O acesso a alguns } \\
\text { estudos que enfocam } \\
\text { mudanças curriculares } \\
\text { nos cursos de } \\
\text { enfermagem denotam } \\
\text { preocupações com } \\
\text { transformações nos } \\
\text { processos formativos, } \\
\text { tendo em vista o } \\
\text { contexto do SUS no } \\
\text { Brasil }\end{array}$ \\
\hline
\end{tabular}




\begin{tabular}{|c|c|c|c|c|c|}
\hline $\begin{array}{c}\text { Contribuição da formação em uma } \\
\text { universidade privada para inserção } \\
\text { dos enfermeiros no mercado de } \\
\text { trabalho }\end{array}$ & $\begin{array}{l}\text { J Nurs } \\
\text { Health. }\end{array}$ & BDENF & 2018 & $\begin{array}{l}\text { Identificar a percepção } \\
\text { do egresso da graduação } \\
\text { em Enfermagem sobre as } \\
\text { contribuições da } \\
\text { universidade privada para } \\
\text { inserção no mercado de } \\
\text { trabalho. }\end{array}$ & $\begin{array}{c}\text { Identificou-se o } \\
\text { sentimento de } \\
\text { satisfação da maioria } \\
\text { dos egressos na sua } \\
\text { formação, de maneira } \\
\text { representativa para a } \\
\text { inserção no mercado } \\
\text { de trabalho e para a } \\
\text { vida profissional. }\end{array}$ \\
\hline $\begin{array}{c}\text { Avaliação do apoio social e } \\
\text { estresse em estudantes de } \\
\text { enfermagem }\end{array}$ & $\begin{array}{l}\text { Rev Esc } \\
\text { Enferm USP }\end{array}$ & Google Scholar & 2018 & $\begin{array}{l}\text { Analisar a percepção de } \\
\text { estresse e de apoio social } \\
\text { dos estudantes de } \\
\text { enfermagem, } \\
\text { considerando o número } \\
\text { de apoiadores e a } \\
\text { satisfação com eles. }\end{array}$ & $\begin{array}{l}\text { A criação de espaços } \\
\text { mais acolhedores no } \\
\text { ambiente acadêmico, a } \\
\text { qualificação do apoio } \\
\text { social e as estratégias } \\
\text { para melhorar a } \\
\text { transição da etapa de } \\
\text { estudante para a de } \\
\text { profissional. }\end{array}$ \\
\hline $\begin{array}{c}\text { O estágio curricular } \\
\text { supervisionado na graduação em } \\
\text { enfermagem: revisão integrativa }\end{array}$ & $\begin{array}{l}\text { Rev Bras } \\
\text { Enferm }\end{array}$ & Google Scholar & 2018 & $\begin{array}{c}\text { Analisar as evidências } \\
\text { disponíveis na literatura } \\
\text { sobre as contribuições do } \\
\text { Estágio Curricular } \\
\text { Supervisionado na } \\
\text { formação em } \\
\text { enfermagem no Brasil e } \\
\text { os métodos de ensino- } \\
\text { aprendizagem } \\
\text { empregados }\end{array}$ & $\begin{array}{c}\text { É um elemento } \\
\text { fundamental na } \\
\text { formação acadêmica, } \\
\text { pois, dependendo da } \\
\text { organização didático- } \\
\text { pedagógica, possibilita } \\
\text { a ressignificação dos } \\
\text { conhecimentos } \\
\text { adquiridos ao longo do } \\
\text { curso e concretiza as } \\
\text { competências } \\
\text { profissionais }\end{array}$ \\
\hline $\begin{array}{c}\text { Internato de enfermagem: } \\
\text { conquistas e desafios na formação } \\
\text { do enfermeiro }\end{array}$ & $\begin{array}{l}\text { Trab. educ. } \\
\text { saúde }\end{array}$ & LILASC & 2018 & $\begin{array}{l}\text { Internato não médico; } \\
\text { enfermagem; educação } \\
\text { em saúde; estudantes de } \\
\text { enfermagem; serviços de } \\
\text { integração docente- } \\
\text { assistencial }\end{array}$ & $\begin{array}{c}\text { O estudo aqui } \\
\text { apresentado procurou } \\
\text { ressaltar a relevância } \\
\text { de se compartilharem } \\
\text { as contribuições } \\
\text { alcançadas com a } \\
\text { prática do internato de } \\
\text { enfermagem }\end{array}$ \\
\hline $\begin{array}{l}\text { Avaliação de Profissionalismo } \\
\text { como competência na formação do } \\
\text { enfermeiro uma revisão integrativa }\end{array}$ & $\begin{array}{l}\text { Revista } \\
\text { Espaço para } \\
\text { a Saúde }\end{array}$ & LILASC & 2019 & $\begin{array}{l}\text { Trata-se de revisão da } \\
\text { literatura com o objetivo } \\
\text { de identificar pelas } \\
\text { evidências na literatura } \\
\text { como é realizada a } \\
\text { avaliação do } \\
\text { profissionalismo nos } \\
\text { cursos de enfermagem no } \\
\text { período de 2014- } 2018 .\end{array}$ & \begin{tabular}{|c|} 
Os estudos científicos \\
analisados \\
identificaram as \\
características e as \\
distintas formas de \\
proceder a avaliação \\
do profissionalismo \\
nos cursos de \\
graduação em \\
enfermagem. \\
\end{tabular} \\
\hline $\begin{array}{c}\text { A produção cientifica sobre vocação } \\
\text { na enfermagem }\end{array}$ & $\begin{array}{l}\text { Rev. Enferm } \\
\text { UFPE }\end{array}$ & BDENF & 2019 & $\begin{array}{c}\text { Analisar a Produção } \\
\text { científica acerca da vocação } \\
\text { em enfermagem em } \\
\text { periódicos nacionais. }\end{array}$ & \begin{tabular}{|} 
Percebeu-se a escassez na \\
produção sobre o tema \\
vocação, bem como a \\
ausência de estudos \\
quantitativos com escalas \\
capazes de medir a \\
vocação do pesquisado.
\end{tabular} \\
\hline $\begin{array}{c}\text { Integralidade do cuidado na formação } \\
\text { do enfermeiro visões e vivências do } \\
\text { acadêmico de enfermagem }\end{array}$ & $\begin{array}{l}\text { Enferm. foco } \\
\text { (Brasília) }\end{array}$ & BDENF & 2019 & $\begin{array}{l}\text { Conhecer as concepções } \\
\text { dos acadêmicos de } \\
\text { enfermagem sobre } \\
\text { integralidade no cuidado } \\
\text { a partir da vivencia ao } \\
\text { longo do curso identificar } \\
\text { como ocorre aplicação } \\
\text { desse princípio da } \\
\text { formação do enfermeiro }\end{array}$ & $\begin{array}{c}\text { O cuidado integral é uma } \\
\text { construção gradual e } \\
\text { ocorre a partir de relações } \\
\text { e reformulação de } \\
\text { modelos } \\
\text { unidimensionais. }\end{array}$ \\
\hline
\end{tabular}




\begin{tabular}{|c|c|c|c|c|c|}
\hline $\begin{array}{l}\text { Percepção de estudantes de } \\
\text { enfermagem sobre o que é ser } \\
\text { enfermeiro }\end{array}$ & $\begin{array}{l}\text { Arq. ciências } \\
\text { saúde } \\
\text { UNIPAR }\end{array}$ & LILASC & 2019 & \begin{tabular}{|c} 
O analisar a percepção dos \\
acadêmicos do $5^{\circ}$ ano de \\
enfermagem sobre o que é \\
"ser enfermeiro". A amostra \\
foi constituída por 22 \\
acadêmicos da Escola de \\
Enfermagem Wenceslau \\
Braz, de Itajubá-MG. Os \\
dados foram coletados por \\
meio de um questionário de \\
caracterização pessoal dos \\
participantes e de um roteiro \\
semiestruturado de grupo \\
focal
\end{tabular} & $\begin{array}{l}\text { O presente estudo } \\
\text { apresentou a percepção } \\
\text { de estudantes de } \\
\text { enfermagem sobre a } \\
\text { prática hospitalar que } \\
\text { realizaram reforçando a } \\
\text { importância de serem } \\
\text { proporcionados espaços } \\
\text { que promovam o diálogo. }\end{array}$ \\
\hline
\end{tabular}

Fonte: Autores.

Relacionado ao recorte temporal de 2015 a 2019, foi evidenciado 18 artigos em português, relacionado à temática do estudo, destes percebemos as produções em 2015 (03); 2017(07) 2018 (04) e 2019 (4).

As pesquisas foram encontradas nas seguintes bases de dados BDENF - Enfermagem (04); LILACS (04); e Google Acadêmico (10).

$\mathrm{Na}$ quarta etapa os artigos selecionados para revisão integrativa foram analisados para a verificação de sua autenticidade, qualidade metodológica, importância das informações e representatividade, por esta razão construirmos um quadro anterior.

Os estudos puderam evidenciar que o delineamento da pesquisa, a análise foi baseada nos níveis 3: evidencias de estudos quase-experimentais e 4: evidências de estudos descritivos (não-experimentais) ou com abordagem qualitativa.

Na quinta etapa, foi constituída da interpretação dos resultados dos artigos relacionados à questão de pesquisa, aonde foi realizada a análise seguindo os passos da análise temática de Bandin descrita por Minayo (2010), que se divide em três etapas.

Na primeira etapa foi realizada a leitura de todos os artigos, para a impregnação do conteúdo permitindo a constituição do corpus, o que valida à abordagem qualitativa. Assim, foi possível delimitar a compreensão dos textos, para evidenciar as unidades de registros, pois a partir as partes que se identificam com o estudo do material tornou possível à formação das unidades temática, em que codificamos e utilizamos os conceitos teóricos levantados para a orientação da análise na etapa.

Na segunda etapa, houve a exploração do material, para encontrar as unidades de registro pelas expressões e palavras significativas, para classificar e agregar os dados no alcance do núcleo de compreensão do texto de forma organizada e sistemática, conforme o quadro a seguir:

Quadro 5: Categorização das Temáticas do Estudo.

\begin{tabular}{|c|c|c|}
\hline Título & Categoria & Unidade Temática \\
\hline Enfermeiro egressos do currículo: integrado e atuação profissional & \multirow{5}{*}{$\begin{array}{c}\text { 1: Principais } \\
\text { inquietações do } \\
\text { egresso de } \\
\text { enfermagem na } \\
\text { inserção aomercado de } \\
\text { trabalho }\end{array}$} & \multirow{5}{*}{$\begin{array}{l}\text { Desafios do egresso de } \\
\text { enfermagem na } \\
\text { inserção ao mercado } \\
\text { de trabalho }\end{array}$} \\
\hline Percepção de estudantes sobre o que é ser enfermeiro & & \\
\hline $\begin{array}{l}\text { Internato de enfermagem: conquistas e desafios na formação do } \\
\text { enfermeiro }\end{array}$ & & \\
\hline Avaliação do apoio social e estresse em estudantes de enfermagem & & \\
\hline $\begin{array}{l}\text { Formação em enfermagem e mundo do trabalho: percepções de } \\
\text { egressos de enfermagem }\end{array}$ & & \\
\hline
\end{tabular}




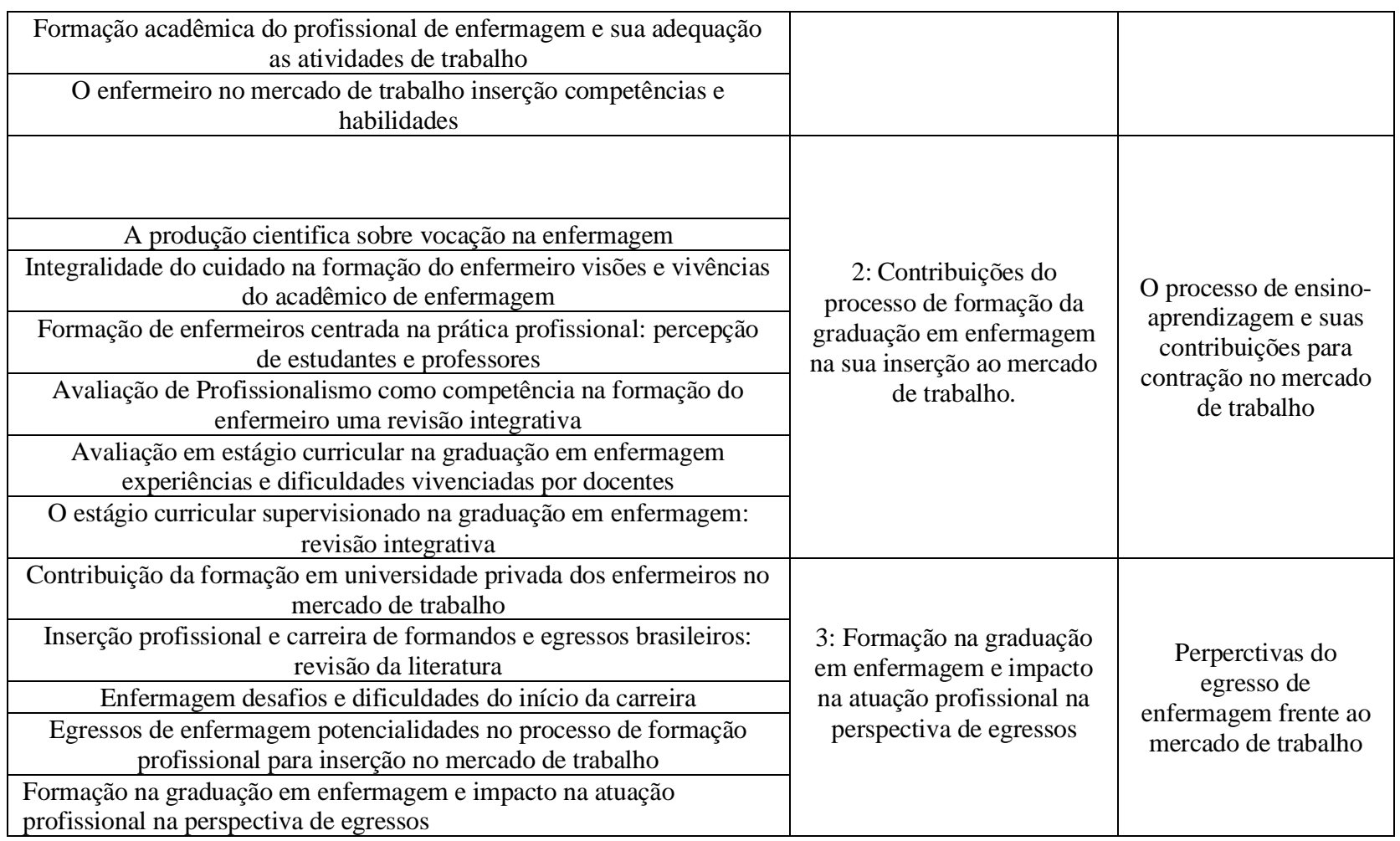

Fonte: Autores.

$\mathrm{Na}$ Terceira etapa, com os dados da análise, foi possível articular o referencial teórico, no que emergiu a identificação da unidade temática "desafios do egresso do egresso de enfermagem na inserção ao mercado de trabalho" as seguintes categorias: I: Principais inquietações do egresso de enfermagem na inserção ao mercado de trabalho. II: Contribuições do processo de formação da graduação em enfermagem na sua inserção ao mercado de trabalho. III: Formação na graduação em enfermagem e impacto na atuação profissional na perspectiva de egressos.

\section{Resultados e Discussão}

\section{Categoria I: Principais inquietações do egresso de enfermagem na inserção ao mercado de trabalho.}

Os enfermeiros desempenham suas funções nas áreas de assistência, educação, pesquisa e gestão, e o cuidado com os seres humanos é o cerne de todas essas atividades. O desenvolvimento das habilidades necessárias para o trabalho em enfermagem deve começar durante a graduação, sendo aprimorado durante anos de prática profissional, capacitando os enfermeiros para desempenhar um papel ativo e crítico na atenção à saúde, contribuindo efetivamente na tomada de decisões, nas questões sociais e institucionais, e refletir diretamente sobre a qualidade do serviço prestado à sociedade (Alves \& Cogo, 2019).

Dentre os estudos investigados, autores referem que os estudantes, ao se formarem e ingressarem no mundo do trabalho, apresentam dificuldades de colocar em prática os modelos de enfermagem e a metodologia de trabalho aprendida, tendo que se adaptar a um sistema funcional meramente assistencial. A integração de atividades teóricas e práticas apoiadas em diferentes métodos de ensino deve promover a integração dos estudantes de enfermagem no contexto da prática em saúde (Barbera et al., 2015; Alves \& Cogo, 2019).

Corroborando ao contexto, cabe ressaltar que o desafio na formação profissional se caracteriza pela educação de cidadãos competentes na aplicação prática dos saberes, com capacidade de compreender, adaptar-se ao mercado de trabalho e encontrar soluções para as situações cotidianas sobre as quais se deve refletir com o intuito de ressignificar o saber. As 
discussões que envolvem o mercado de trabalho na saúde convergem na visão de uma educação capaz de unir teoria e prática, possibilitando ao enfermeiro competências para agir diante de um contexto de incertezas (Costa \& Menezes, 2017).

Ressaltam-se ainda que, os egressos citam outros aspectos negativos do mundo do trabalho os quais não foram suficientemente refletidos e discutidos durante a graduação: a elevada e contínua inserção da tecnologia no trabalho em saúde, a precarização dos recursos humanos em termos qualitativo e quantitativo, o ritmo de trabalho elevado, a escassez de materiais, as relações de poder e de hierarquias extremamente marcadas (Souza et al., 2017).

Autores corroboram que as exigências para a inserção no mercado de trabalho têm aumentado, fazendo com que os egressos aspirem, principalmente, por cursos de especialização e residências que têm como foco a qualificação e aprimoramento das habilidades técnicas (Puschel et al., 2017).

Em contrapartida, o estresse na vida do acadêmico em enfermagem, (Des)conhecimento e prevenção, que o estresse pessoal está relacionado a situações de desequilíbrio, bem como a dificuldades na vida profissional, tais como: excesso de trabalho e falta de vocação, sendo que ambas as dimensões (excesso de trabalho e falta de vocação) trazem consequências tanto para o físico, quanto para o mental (Sanematsu et al., 2019).

Nesse sentido, no que se refere ao estresse, os estudantes apresentaram baixa intensidade na maioria dos domínios mensurados, com exceção do domínio formação profissional, sugerindo insegurança quanto à transição do papel de estudante para o de profissional e ao ingresso no mercado de trabalho altamente competitivo (Almeida et al., 2018).

Entende-se por "estresse" ou "estressores" qualquer demanda, interna ou externa, que exceda os recursos individuais disponíveis para lidar com determinada situação. Trata-se, portanto, da relação entre o sujeito e o ambiente e da atribuição de significados aos eventos cotidianos. Em relação ao conhecimento produzido acerca do estresse entre estudantes de enfermagem, duas perspectivas de estudo foram identificadas na literatura: a primeira se refere à investigação de fatores/elementos potencialmente estressores no cotidiano e as implicações para a saúde mental desses sujeitos, e a segunda vertente compõe as estratégias de enfrentamento para a manutenção do bem-estar no contexto universitário (Almeida et al., 2018).

Destaca-se que o apoio de familiares, amigos, vizinhos ou colegas tem sido descrito na literatura como uma ferramenta importante para o enfrentamento do estresse, pois auxilia o indivíduo a superar seus problemas, ameniza sua vulnerabilidade situacional e pode contribuir para a adoção de estilos de vida saudáveis e tomada de decisões mais responsáveis (Almeida et al., 2018)

\section{Categoria II: Contribuições do processo de formação da graduação em enfermagem na sua inserção ao mercado de trabalho.}

O Estagio Curricular Supervisionado possui papel central na formação profissional de enfermeiros porque não se restringe aos muros da academia e tampouco ao desenvolvimento técnico, mecânico, dos futuros profissionais para o desempenho de atividades laborativas inerentes à profissão. Ele possibilita a inserção do estudante na realidade de saúde do Sistema Único, tal qual ela se apresenta, sem manipulações ou mesmo adequações para a realização dos processos de ensinoaprendizagem (Esteves et al., 2018).

Ressalta-se ainda que, estágio curricular pode ser considerado como um componente que proporciona a aproximação da academia com o ambiente fora da universidade, estreitando as relações entre o ensino e o campo de trabalho buscando formar profissionais cada vez mais preparados, que sejam capazes de problematizar e propor soluções atuando de forma crítica-reflexiva (Paiano et al., 2015). 
Os autores ainda complementam que o estágio curricular permite uma experiência real do que foi visto em sala de aula e exige que o aluno aplique todo o conteúdo estudado durante o curso para direcionar suas atividades e desenvolver sua capacidade para enfrentar as situações com as quais irá se deparar enquanto profissional (Paiano et al., 2015).

Durante a formação de profissionais para atuação no cuidado à saúde das pessoas faz se necessário o desenvolvimento de competências fundamentais para atuar com o paciente, família e comunidade. Assim, o processo de ensino-aprendizagem, envolvendo o processo de avaliação, deve possibilitar a construção do perfil de profissional capacitado a promover o cuidado integral do ser humano, com vistas à integralidade (Marçal et al., 2019).

Os acadêmicos estão sendo preparados para uma melhor formação, tornando-se aptos a fazer a diferença dentro da sociedade. A inserção da integralidade do cuidado como um dos eixos para uma melhoria na formação do profissional enfermeiro é uma garantia da qualidade de assistência com um olhar inovador (Santos et al., 2019).

Para alguns autores, é durante o Estágio Curricular Supervisionado que o estudante exercitará o papel de gerente da assistência de enfermagem, fomentando o desenvolvimento de habilidades gerenciais: liderança, tomada de decisão, trabalho em equipe, comunicação, dentre outras (Esteves et al., 2018).

Em consonância ao contexto, vale destacar o aspecto importante para que este fortalecimento do SUS ocorra de maneira gradativa e contínua é a inserção dos estudantes nos diferentes níveis de atenção à saúde. Com esta iniciativa será possível para o estudante vivenciar o modelo de saúde pública existente no contexto nacional e uma vez conhecendo este modelo de prática profissional, poderá refletir sobre a mesma, para no futuro contribuir de maneira mais efetiva com a transformação deste sistema (Tonhon et al., 2017).

Para atingir um degrau mais elevado da assistência, prezando pelo cuidado integral, os diferentes profissionais detentores dos saberes científicos devem compartilhar e traçar seus caminhos, interligando estratégias que visem o benefício dos usuários e uma assistência completa e humanizada.

A formação profissional não pode ter como referência apenas a doença da pessoa, aplicando de forma única o modelo biomédico que objetiva o cuidado voltado ao diagnóstico e a busca pelo tratamento, mas deve compreender as pessoas de forma ampla, contemplando todas as necessidades apresentadas (Santos et al., 2019).

A inserção do estudante nos diversos cenários da prática profissional pode ser operacionalizada ao final do curso, processo geralmente conhecido como "Estágio supervisionado". Neste modelo de inserção na prática profissional é oportunizado aos estudantes a possibilidade de consolidação dos desempenhos trabalhados no decorrer da graduação, favorecendo uma integração mais consistente entre a teoria e prática. Dessa forma, esses estudantes podem atuar nos espaços da prática profissional como agentes provocadores de mudanças sociais da saúde, com repercussões no fortalecimento do SUS (Tonhon et al., 2016).

\section{Categoria III: Formação na graduação em enfermagem e impacto na atuação profissional na perspectiva de egressos.}

O ensino em enfermagem tem sido foco de muitos estudos e debates, principalmente após a instituição das Diretrizes Curriculares Nacionais (DCN), gerando uma série de reestruturações na formação profissional como não reduzir a formação profissional de enfermeiros ao mero desenvolvimento de competências técnicas e instrumentais, incorporação de metodologias ativas de aprendizagem, promover edificação profissional pautada pelos princípios da integralidade da assistência, considerando o Sistema Único de Saúde como eixo estruturante do processo formativo, além da incorporação do Estágio Curricular Supervisionado (ECS). Todas as reestruturações propostas desde 1996, ano da promulgação da Lei de Diretrizes e Bases para a Educação Nacional, têm contribuído para que o ensino em enfermagem avance em direção do desenvolvimento do pensamento complexo, visando formar profissionais mais críticos e reflexivos, capazes de atuar nas mais diversas situações, propondo soluções aos problemas encontrados (Pafume et al., 2018). 
O segundo aspecto revela-se pela importância de pesquisar sobre o momento de transição da universidade para o mercado de trabalho, ao longo da formação universitária, crises vocacionais podem ressurgir, pela necessidade de reafirmar a escolha profissional e também de se deparar efetivamente com a realidade ocupacional da profissão escolhida. Outros pontos destacados pela literatura que podem contribuir para dificuldades características deste momento seriam: falta de planejamento de carreira, dificuldades em atuar na área de formação, constatação do distanciamento entre o que foi aprendido na universidade e o que é esperado na prática profissional, desistência da busca pela satisfação profissional, realização de trabalhos alternativos e abandono do exercício profissional (Gusmão \& Socci, 2017).

O processo de formação do enfermeiro mantém uma íntima ligação com a conformação do mercado de trabalho e, para se adequar a ele, a qualificação e a formação dos profissionais de Enfermagem devem estar inter-relacionadas. Inicialmente, a formação do profissional de Enfermagem no Brasil, e na maioria dos países era direcionada para o atendimento e prestação de cuidados no âmbito dos hospitais civis e militares, e posteriormente, a profissão foi se qualificando e expandindo. Atualmente, a sua atuação está presente em diferentes serviços de saúde como Hospital Geral, Centro de Atenção Psicossocial (CAPS), Ambulatórios e Estratégia Saúde da Família (ESF), serviços esses encontrados nos espaços coletivos tornando uma perspectiva atraente no mercado de trabalho dos enfermeiros (Lima et al., 2017).

Juntamente com a ampliação dos postos de trabalho para estes profissionais houve uma expressiva expansão dos cursos e vagas na área de Enfermagem sendo a expansão dessas, ainda insuficiente para atender às múltiplas e diversas demandas de atenção à saúde da população nos níveis locais, regionais e nacionais (Lima et al., 2017).

Neste conjunto de ações, necessárias para avaliação interna, destaca-se a perspectiva dos egressos, determinante na definição da qualidade da formação, uma vez que o egresso é quem confronta a bagagem teórico científica, técnica, ética e humana que vivenciou no ambiente universitário com as exigências requeridas no exercício profissional. O traçado do perfil do egresso é necessário para a compreensão daquilo que é esperado do estudante ao longo de sua trajetória formativa. Estabelecer diálogo entre a formação e a atuação pode subsidiar a reflexão sobre como encaminhar mudanças na formação atendendo-se ao perfil definido pelas orientações para a formação de enfermeiros (Rodrigues et al., 2015).

Quando se trata do enfermeiro recém-formado, a insegurança e o medo perante as dificuldades tornam-se desafios iniciados no processo de admissão ao primeiro emprego, continuando com seu processo de adaptação ao serviço. Assim, o desafio pode ser entendido como um estímulo para a superação de uma situação adversa. Envolve ainda a possibilidade de transformação de tal situação, em subsídio para o próprio crescimento, desenvolvimento ou conquista. Isso porque, ao adentrar ao universo de trabalho, os enfermeiros recém-formados encontram-se perante situações adversas que decorrem da falta de integração entre o que é ensinado no curso de graduação e a realidade no atendimento de saúde (Wader, 2017).

A diferença entre a educação implementada na graduação e a exigência do mercado de trabalho têm causado dificuldades aos egressos na adequação deles em sua vida profissional. É necessário, dessa maneira, ampliar o conhecimento acerca dos egressos do curso de graduação em enfermagem para que seja realizada e complementada a avaliação do processo de aprendizagem, objetivando conhecer o potencial formador da instituição, as exigências da sociedade, o produto final do trabalho pedagógico e a absorção desses profissionais no mercado de trabalho (Canever et al., 2017).

\section{Considerações Finais}

Conclui-se que, a partir da construção de uma leitura reflexiva baseada nos artigos teóricos utilizados para construção deste ensaio, evidenciou em grandes partes dos estudos utilizados que as maiores porcentagens deles vislumbram, o comprometimento no processo de ensino-aprendizagem como grande ofensor e contribuir da insegurança deste enfermeiro recém-formado. 
Ainda no que se refere no processo ensino-aprendizado cabe mencionar que alguns autores descrevem como resultado de seus estudos a ineficácia das ações práticas durante o estágio supervisionado interligando a insegurança dos alunos à não execução de procedimento e ações do enfermeiro em construção

Por sua vez, baseado no aumento das complexidades frente ao processo patológico e ainda nas problemáticas advindas do contexto saúde doença as instituições hospitalares investem na realização processos de seleção, não oportunizando acesso de recém-formado tendo vista a solicitação de experiência pregressas na assistência e/ou curso de pós-graduação latusenso, dificultando assim o acesso ao mercado de trabalho.

Por fim, identificou-se ainda que mesmo após a inserção ao mercado de trabalho as construções teóricas registram inquietações do egresso de enfermagem ao cuidado assistencial ao paciente, desde sua concepção ao processo morte e morrer. Este profissional em construção vivencia diversas situações que, não se sente preparado para confrontar, aumentando sua exposição aos fatores estressores e ainda, as complexidades advindas do processo de cuidado e autocuidado.

\section{Referências}

Almeida, L. Y. D., Carrer, M. O., Souza, J. D., \& Pillon, S. C. (2018). Avaliação do apoio social e estresse em estudantes de enfermagem. Revista da Escola de Enfermagem da USP, 52.

Alves, E. A. T. D., \& Cogo, A. L. P. (2014). Percepção de estudantes de enfermagem sobre o processo de aprendizagem em ambien te hospitalar. Revista Gaúcha de Enfermagem, 35(1), 102-109.

André, S. R., Rodrigues, I. L. A., Nogueira, L. M. V., de Almeida Santos, M. N., \& de Moraes, T. M. (2019). Responsabilidade técnica em enfermagem: conhecendo sua importância para o exercício profissional. Enfermagem em Foco, 10.

Araújo, T. A. D. S., Reis, P. P., Castro, C. D., Oliveira, L. B. D., Santos, K. B. D., Carbogim, F. D. C., \& Püschel, V. A. D. A. (2019). Inserção profissional de Egressos da Licenciatura: avaliação quantitativa. Rev. Paul. Enferm. (Online), 1-12.

Azevedo, D. M. D., Azevedo, I. C. D., Holanda, C. S. M. D., Santos, Q. G., Vale, L. D., \& Cassiano, A. D. N. (2013). Da academia à realidade: uma reflexão acerca da prática do exame físico nos serviços de saúde. Saúde \& Transformação Social, 4(4), 106-110.

Boostel, R., Felix, J. V. C., Bortolato-Major, C., Pedrolo, E., Vayego, S. A., \& de Fátima Mantovani, M. (2018). Estresse do estudante de enfermagem na simulação clínica: ensaio clínico randomizado. Revista Brasileira de Enfermagem, 71(3).

Brasil, Ministério da Educação (2015). Número de Universitário cresce em 10 anos. http:www.brasil.gov.br/educacao/2015/12numero-de-estudantesuniversitarios-cresce-25-em-10anos>.

Brasil, Ministério da Saúde (2017). Diretrizes curriculares. https://bvsms.saude.gov.br/bvs/saudelegis/gm/2017/prt2436_22_09_2017.html

Brasil. Ministério da Educação (2001). Diretrizes Curriculares Nacionais do Curso de Graduação em Enfermagem. http://portal.mec.gov.br/dmdocuments/ces1133.pdf

Canever, B. P., Gomes, D. C., Jesus, B. H. D., Spillere, L. B., Prado, M. L. D., \& Backes, V. M. S. (2014). Processo de formação e inserção no mercado de trabalho: uma visão dos egressos de enfermagem. Revista Gaúcha de enfermagem, 35(1), 87-93.

Carvalho, A. C. D. (1972). Orientação e ensino de estudantes de enfermagem no campo clínico.

Costa, T. V., \& Guariente, M. H. D. D. M. (2017). Enfermeiros egressos do currículo integrado: inserção e atuação profissional. Rev. enferm. UFPE on line, $77-85$.

Esteves, L. S. F., Cunha, I. C. K. O., Bohomol, E., \& Negri, E. C. (2018). O estágio curricular supervisionado na graduação em enfermagem: revisão integrativa. Revista Brasileira de Enfermagem, 71.

Garcia, S. D., Vannuchi, M. T. O., Garanhani, M. L., \& De Sordi, M. R. L. (2018). Internato de enfermagem: conquistas e desafios na formação do enfermeiro. Trabalho, Educação e Saúde, 16(1), 319-336.

Gusmão, C. A. \& Socci, V. (2017). Inserção profissional e carreira de formandos e egressos brasileiros: revisão da literatura. Revista Brasileira de Orientação Profissional, 18(1),81-92.

Hirsch, C. D., Barlem, E. L. D., Almeida, L. K. D., Tomaschewski-Barlem, J. G., Figueira, A. B., \& Lunardi, V. L. (2015). Estratégias de coping de acadêmicos de enfermagem diante do estresse universitário. Revista Brasileira de Enfermagem, 68(5), 783-790.

Lakatos, E. M.; \& MarconI, N. A. (2010) Fundamentos de Metodologia Cientifica. (7a ed.), Ed. Atlas.

Lima, A. F., Lopes, L. C. S., Soane, A. M. N. C., \& Fortes, A. F. A. (2017). Egressos de enfermagem: potencialidades no processo de formação profissional para inserção no mercado de trabalho. Indagatio Didactica, 9(4), 65-80. 
Research, Society and Development, v. 10, n. 3, e23010312660, 2021 (CC BY 4.0) | ISSN 2525-3409 | DOI: http://dx.doi.org/10.33448/rsd-v10i3.12660

Lopes Neto, D., Teixeira, E., Vale, E. G., Cunha, F. S., Xavier, I. D. M., Fernandes, J. D \& Bocardi, M. I. B. (2007). Aderência dos cursos de graduação em enfermagem às diretrizes curriculares nacionais. Revista Brasileira de Enfermagem, 60(6), 627-634.

Machado, M., de Oliveira, E., Lemos, W., de Lacerda, W., Filho, W., Wermelinger, M., Vieira, M., dos Santos, M., Junior, P., Justino, E., \& Barbosa, C. (2016). Mercado de trabalho da enfermagem: Aspectos gerais. Enfermagem em Foco, 7(ESP), 35-53.

Marçal, A. D. R. V., Ribeiro, E. R., \& Zagonel, I. P. S. (2019). Avaliação de profissionalismo como competência na formação do enfermeiro: uma revisão integrativa. Revista Espaço para a Saúde, 75-86.

Minayo, M. C. S. (2013). O desafio do conhecimento: pesquisa qualitativa em saúde. (13a ed.), Hucitec.

Moura, J. M. Nobre, R.S. Alves, R.M. (2016). Qualidade de vida de estudantes de graduação em enfermagem. Revista Gaúcha de Enfermagem, 37(2), e55291

Oliveira, W. A. (2016). Enfermagem: desafios e dificuldades no início da carreira. Revista de Enfermagem da FACIPLAC, 2(2).

Ortega, M. D. C. B., Cecagno, D., Llor, A. M. S., de Siqueira, H. C. H., Montesinos, M. J. L., \& Soler, L. M. (2015). Formação acadêmica do profissional de enfermagem e sua adequação às atividades de trabalho. Revista Latino-Americana de Enfermagem, 23(3), 404-410.

Pafume, S. M., da Silva, É. C., \& de Carvalho Andrade, A. (2018). Contribuição da formação em uma universidade privada para inserção dos enfermeiros no mercado de trabalho. Journal of Nursing and Health, 8(1).

Paiano, L. A. G., Rodrigues, R. M., Conterno, S. D. F. R., \& Camboin, F. F. (2015). Avaliação em estágio curricular na graduação em enfermagem: experiências e dificuldades vivenciadas por docentes. Educere et Educare, 10(19).

Püschel, V. A. D. A., Costa, D., Reis, P. P., Oliveira, L. B. D., \& Carbogim, F. D. C. (2017). O enfermeiro no mercado de trabalho: inserção, competências e habilidades. Revista Brasileira de Enfermagem, 70(6), 1220-1226.

Rodrigues, R. M., Conterno, S. D. F. R., \& Guedes, G. C. (2015). Formação na graduação em enfermagem e impacto na atuação profissional na perspectiva de egressos. Interfaces da Educação, 6(17), 26-43.

Sanematsu, L. S. A., Folquitto, C. T. F., \& Martins, M. D. C. F. (2019). A produção científica sobre vocação na enfermagem. Rev. enferm. UFPE on line, 819828 .

Santos, A. T. S., Oliveira, C. B. D., Passos, M. D. C., Andrade, A. D. S. A., \& Gallotti, F. C. M. (2019). Integralidade do cuidado na formação do enfermeiro: visões e vivências do acadêmico de enfermagem. Enferm. foco (Brasília), 122-126.

Silva, A. N. C. D., Moreira, D. P., Freitas, C. M. A. D., Teixeira, A. K. S., \& Pinheiro, A. R. M. (2019). Estágio extracurricular de enfermagem: estratégia para a formação profissional. Enferm. foco (Brasília), 129-135.

Silva, B. L. G., da Silva Alves, E., \& Fortes, A. F. A. (2019). Percepção de estudantes de enfermagem sobre o que é ser enfermeiro. Arquivos de Ciências da Saúde da UNIPAR, 23(2).

Silva, L. A. A. D., Ferraz, F., Lino, M. M., Backes, V. M. S., \& Schmidt, S. M. S. (2010). Educação permanente em saúde e no trabalho de enfermagem: perspectiva de uma práxis transformadora. Revista Gaúcha de Enfermagem, 31(3), 557-561.

Sousa, T. F., Fonseca, S. A., José, H. P. M., \& Nahas, M. V. (2013). Validade e reprodutibilidade do questionário Indicadores de Saúde e Qualidade de Vida de Acadêmicos (Isaq-A). Arquivos de Ciências do Esporte, 1(1).

Sousa, L. L. (2016). Resenha-Estágios supervisionados na formação docente: educação básica e educação de jovens e adultos. Revista Internacional de Formação de Professores, 155-163.

Souza, N. V. D. O.; Pires, A. S.; Gonçalves, F. G. A.; Tavares, K. F. A.; Baptista, A. T. P. (2017). Formação em enfermagem e mundo do trabalho: percepções de egressos de enfermagem. Aquichan, 17(2), 204-216.

Tonhom, S. F. D. R., Moraes, M. A. A. D., \& Pinheiro, O. L. (2016). Formação de enfermeiros centrada na prática profissional: percepção de estudantes e professores. Revista Gaúcha de Enfermagem, 37(4). 